\title{
Deterrent activity of plant lectins on cowpea weevil Callosobruchus maculatus (F.) oviposition
}

\author{
Amin Sadeghi ${ }^{\text {a,b }}$, Els J.M. Van Damme ${ }^{\text {b }}$, Willy J. Peumans ${ }^{\text {b }}$, Guy Smagghe ${ }^{\text {a,* }}$

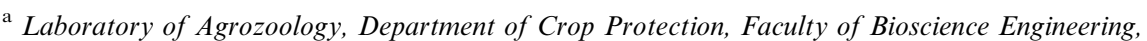 \\ Ghent University, Coupure links 653, B-9000 Ghent, Belgium \\ ${ }^{\mathrm{b}}$ Laboratory of Biochemistry and Glycobiology, Department of Molecular Biotechnology, Faculty of Bioscience Engineering, \\ Ghent University, Coupure links 653, B-9000 Ghent, Belgium
}

Received 10 March 2006; received in revised form 21 June 2006

Available online 2 August 2006

\begin{abstract}
A set of 14 plant lectins was screened in a binary choice bioassay for inhibitory activity on cowpea weevil Callosobruchus maculatus (F.) oviposition. Coating of chickpea seeds (Cicer arietinum L.) with a $0.05 \%$ (w/v) solution of plant lectins caused a significant reduction in egg laying. Control experiments with heat inactivated lectin and BSA indicated that the observed deterrent effects are specific and require carbohydrate-binding activity. However, no clear correlation could be established between deterrent activity and sugar-binding specificity/molecular structure of the lectins. Increasing the insect density reduced the inhibitory effect of the lectins confirming that female insects are capable of adjusting their oviposition rates as a function of host availability.
\end{abstract}

(C) 2006 Elsevier Ltd. All rights reserved.

Keywords: Plant lectin; Cowpea weevil; Callosobruchus maculatus; Binary choice assay; Oviposition; Egg development

\section{Introduction}

The cowpea weevil Callosobruchus maculatus (F.) is a major insect pest for grain legumes in many tropical and subtropical countries (Singh, 1997). Estimated annual losses caused by this insect in West Africa alone exceed $\$ 50$ million (Shade et al., 1986). Chemical control of cowpea weevil has become cumbersome because the intensive application of conventional neurotoxic insecticides already resulted in the development of insecticide resistant strains. Moreover, the application of insecticides has a severe impact on both food and feed safety, and the quality of the environment (Zettler and Cuperus, 1990; Silver, 1994). Public awareness of the risks inherent to the use of pesticides stimulated the search for and development of environmentally friendly alternatives for the control of insect pests.

\footnotetext{
* Corresponding author. Tel.: +329 2646150; fax: +32 92646239.

E-mail address: guy.smagghe@ugent.be (G. Smagghe).
}

During the last years natural products with insecticidal activity and low mammalian toxicity have been put forward as protective agents for stored staple crops (Elhag, 2000; Boeke et al., 2004; Shaaya et al., 1997). Besides crude extracts and volatile oils several types of plant proteins have been identified that exert toxic or detrimental effects on insects. Classical examples of such proteins are trypsin inhibitors, chitinases and carbohydrate-binding proteins known as lectins. Previous studies indicated that some but certainly not all plant lectins possess a more or less pronounced entomotoxic or insecticidal activity (Peumans and Van Damme, 1995; Carlini and Grossi-de-Sa, 2002). Most probably, the obvious differences in toxicity are somehow related to the fact that plant lectins are a complex composite of multiple families of evolutionary related proteins with markedly different biochemical and physicochemical properties, carbohydrate-binding specificity and biological activities (Van Damme et al., 1998a,b). During the last two decades numerous reports were published on the insecticidal activity of plant lectins against many insect pests 
belonging to the orders of Lepidoptera, Coleoptera, Diptera and Homoptera (Boulter et al., 1990; Gatehouse et al., 1995; Hilder et al., 1995; Sharma et al., 2004). Interestingly, some of these reports provided evidence for a moderate to strong inhibition for dietary lectins on larval development of C. maculatus (Murdock et al., 1990; Oliveira et al., 1999; Omitogun et al., 1999; Machuka et al., 2000; Zhu-Salzman et al., 2003; Sharma et al., 2004).

To further corroborate the potential anti-insect activity on the cowpea weevil we examined whether plant lectins possibly act through a different mechanism based on a reduction of the infestation rate, e.g. by a decreased egg deposition. Chickpea seeds were treated with a set of purified lectins comprising members of four distinct families and exposed to adult cowpea weevils.

\section{Results}

\subsection{Plant lectins and C. maculatus oviposition}

To investigate the possible deterrent activity on oviposition by $C$. maculatus a panel of 14 lectins was selected. As shown in Table 1, this set of lectins comprises members of four different lectin families and covers a broad range of carbohydrate-binding specificities. Since the envisaged experiments required reasonable quantities of purified proteins the choice of the lectins was partly determined by the feasibility to isolate large amounts of the lectin.

Preliminary experiments with chickpeas treated with a $0.05 \%(\mathrm{w} / \mathrm{v})$ solution indicated that all lectins included in our assay caused a reduction in oviposition by $C$. maculatus but also revealed obvious differences in activity. Prior to set up elaborated experiments with all lectins, the assay system was optimized with two lectins. For this purpose the Arum maculatum (AMA) and peanut or Arachis hypogaea agglutinin (PNA) were selected because (i) both lectins consis- tently exhibited a high deterrent activity in the preliminary assay and (ii) represent two different lectin families with a totally different specificity.

\subsection{AMA and PNA cause a dose-dependent reduction of the C. maculatus oviposition}

To confirm that the reduction of the oviposition observed in the preliminary assays was caused by the lectins a first series of experiments was set up to investigate the dose dependence of the deterrent activity. Chickpeas were treated with AMA and PNA at different concentrations $(0.0005 \%, 0.005 \%$ and $0.05 \%, \mathrm{w} / \mathrm{v})$ and exposed to 20 C. maculatus adults. As shown in Table 2 and Fig. 1, both lectins significantly reduced $(p \leqslant 0.01)$ the oviposition by approximately $60 \%$ when applied at a concentration of $0.05 \%$. However, at lower concentrations there was no significant effect $(p>0.1)$ indicating that a minimal dose is

Table 2

Deterrent activity of AMA, PNA, BSA against oviposition of $20 C$. maculatus adults

\begin{tabular}{lcl}
\hline Lectin & $\%$ Deterrent activity & $p$-value \\
\hline AMA $0.05 \%$ & 60.1 & $3 \mathrm{E}-15$ \\
AMA 0.005\% & 6.7 & 0.45 \\
AMA 0.0005\% & -12.8 & 0.27 \\
PNA 0.05\% & 64.4 & 0.01 \\
PNA 0.005\% & 14.5 & 0.36 \\
PNA 0.0005\% & 11.5 & 0.42 \\
BSA 0.05\% & 16.8 & 0.14 \\
BSA 0.005\% & -19.6 & 0.17 \\
Autoclaved AMA 0.05\% & -0.5 & 0.97 \\
Control (water only) & 12.8 & 0.10 \\
\hline
\end{tabular}

${ }^{a}$ Data are expressed as mean percentages of deterrent activity, based on a minimum of 2 repeated experiments, each consisting of 2-3 oviposition boxes.

b $p$-values after Student's $t$-test (2-tailed) comparing the effect in the treatment with the control.

Table 1

List of 14 lectins used in the experiment

\begin{tabular}{llllll}
\hline Lectin abbreviation & Plant species & Common name & Lectin family & Carbohydrate specificity $^{\mathrm{a}}$ & Molecular structure $^{\mathrm{b}}$ \\
\hline UDA & Urtica dioica & Stinging nettle & Hevein-family & $(\mathrm{GlcNAc})_{n}$ & {$[\mathrm{P} 9]$} \\
WGA & Triticum aestivum & Wheat germ & Hevein-family & $(\mathrm{GlcNAc})_{n}$ & {$[\mathrm{P} 18]_{2}$} \\
Jacalin & Artocarpus integrifolia & Jackfruit & Jacalin-related & Gal/GalNAc, Gal $\beta(1,3) \mathrm{GalNAc}$ & {$[\mathrm{P}(15+2)]_{4}$} \\
Morniga-G & Morus nigra & Mulberry & Jacalin-related & Gal/GalNAc, Gal $\beta(1,3) \mathrm{GalNAc}$ & {$[\mathrm{P}(15+2)]_{4}$} \\
Con A & Canavalia ensiformis & Jack bean & Legume lectins & Man/Glc & {$[\mathrm{P} 26]_{4}$} \\
PHA & Phaseolus vulgaris & Common bean & Legume lectins & Complex & {$[\mathrm{P} 31]_{4}$} \\
PNA & Arachis hypogaea & Peanut & Legume lectins & Gal & {$[\mathrm{P} 27]_{4}$} \\
RPA & Robinia pseudoacacia & Black locust & Legume lectins & Complex & {$[\mathrm{P} 29]_{4}[\mathrm{P} 31]_{4}$} \\
AMA & Arum maculatum & Lords and ladies & GNA-related & Man & {$[\mathrm{P}(12+12)]_{2}$} \\
APA & Allium porrum & Leek & GNA-related & Man & {$[\mathrm{P} 13]_{2}$} \\
ASA & Allium sativum & Garlic & GNA-related & Man & {$[\mathrm{P} 12]_{2}$} \\
GNA & Galanthus nivalis & Snowdrop & GNA-related & Man & {$[\mathrm{P} 12]_{4}$} \\
NPA & Narcissus pseudonarcissus & Daffodil & GNA-related & Man & {$[\mathrm{P} 12]_{2}$} \\
TxLC-I & Tulipa sp. & Tulip & GNA-related & Man/GalNAc & {$[\mathrm{P}(14+14)]_{4}$} \\
\hline
\end{tabular}

${ }^{a}$ Gal, galactose; GalNAc, $N$-acetylgalactosamine; Glc, glucose; GlcNAc, $N$-acetylglucosamine; Man, mannose.

${ }^{\mathrm{b}}[\mathrm{P} X]$ stands for protomer with a molecular mass of $X \mathrm{kDa}$. $[\mathrm{P}(Y+Z)]$ indicates that the protomer is cleaved in two polypeptides of $Y$ and $Z \mathrm{kDa}$.

${ }^{c}$ The lectin is a mixture of isolectins composed of two different subunits that associate randomly. Agglutination activity of lectins with complex specificity cannot be inhibited by any simple sugar, but only by more complex glycoproteins. 


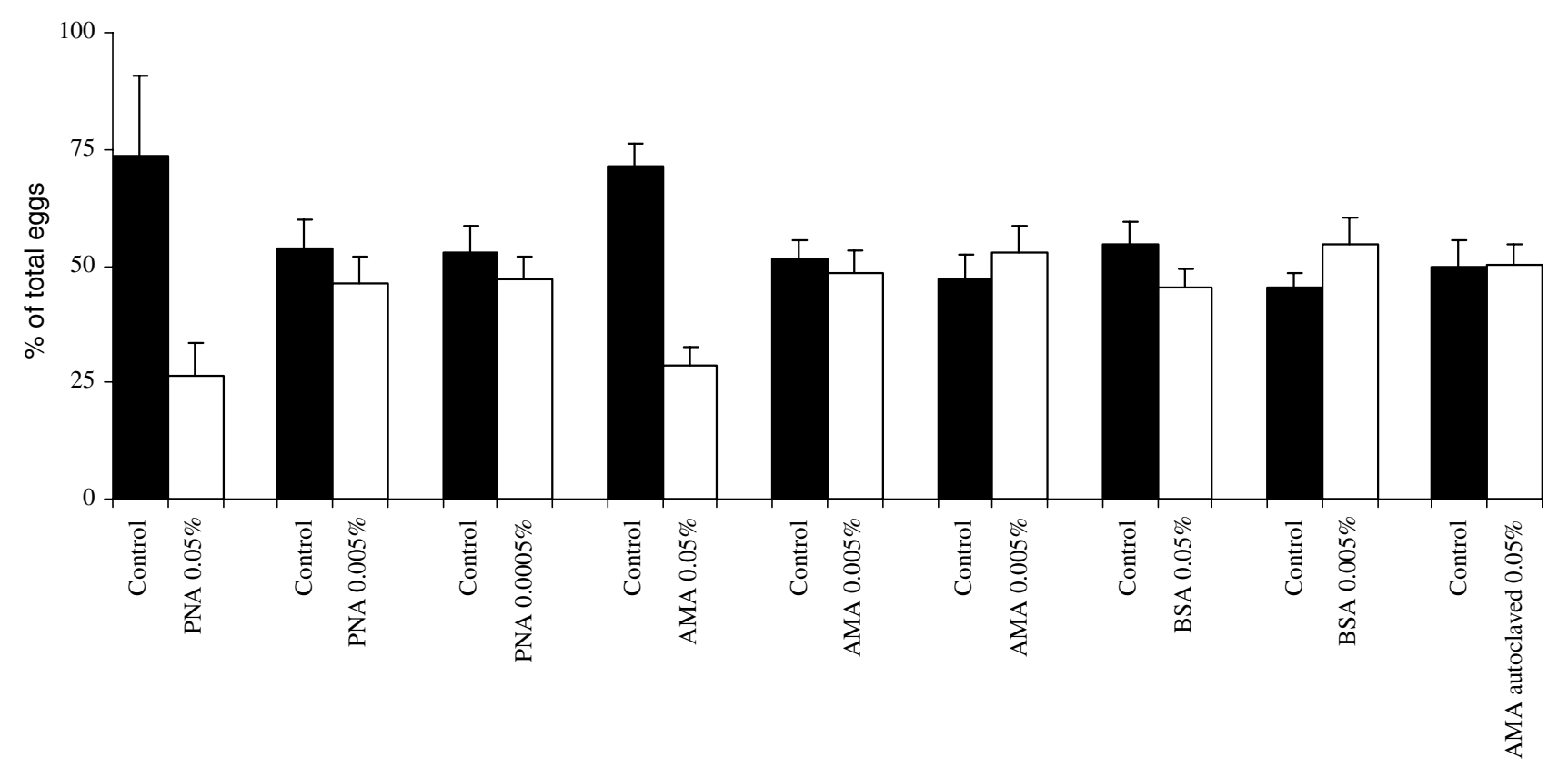

Fig. 1. Distribution of eggs deposited by 20 C. maculatus adults in the oviposition chamber with control seeds and seeds coated with lectin (AMA or PNA) at different concentrations $(0.05 \%, 0.005 \%$ and $0.0005 \%)$, BSA $(0.05 \%, 0.005 \%)$ or autoclaved lectin AMA $(0.05 \%)$. The total number of eggs laid in each treatment was set at $100 \%$. Data are expressed as means \pm SEM, based on a minimum of two repeated experiments, each consisting of $2-3$ oviposition boxes.

required to cause a reduction of the oviposition. BSA included in the same assay had no effect, suggesting that the observed activity of AMA and PNA is specific and cannot be observed for every protein. Heat inactivation completely abolished the inhibitory activity of AMA indicating that the carbohydrate-binding activity of the lectin is required for its deterrent effect.

\subsection{Comparison of the deterrent activity of all 14 lectins in a binary choice assay}

To compare the deterrent activity of all 14 lectins listed in Table 1, lectins were tested at a concentration of $0.05 \%$ in a binary choice assay with 20 unsexed adult beetles in the oviposition chamber. Under these conditions all 14 lectins scored a significant $(p<0.01)$ deterrent activity on the oviposition of 20 bruchid beetles (Table 3 and Fig. 2). The strongest $(p<0.001)$ effect on oviposition was recorded for the bean lectin PHA (78.1\%). Other lectins showed a deterrent activity ranging between $66.4 \%$ and $36.5 \%$. The tulip lectin TxLC-I exhibited the lowest, but still significant $(p=0.03)$ deterrent activity (Fig. 3).

A closer examination of the data revealed no clear link between deterrent activity and sugar-binding specificity or molecular structure of the lectins. According to the results of the comparative assays lectins with an exclusive specificity towards complex $N$-glycans such as PHA and RPA are among the most active. GNA-related lectins with a specificity that is primarily directed against high mannose $\mathrm{N}$-glycans (like AMA, APA, ASA, GNA and NPA) are fairly active as they caused a reduction of oviposition in the range of $45-66 \%$. ConA, which has a strong affinity for
Table 3

Deterrent activity of 14 plant lectins against oviposition of 20 C. maculatus adults

\begin{tabular}{lll}
\hline Lectin, $0.05 \%$ & $\%$ Deterrent activity & $p$-value \\
\hline PHA & 78.1 & $1 \mathrm{E}-8$ \\
NPA & 66.4 & $8 \mathrm{E}-6$ \\
PNA & $64.4^{\mathrm{c}}$ & 0.01 \\
ConA & 64.1 & $2 \mathrm{E}-3$ \\
GNA & 64.1 & $2 \mathrm{E}-5$ \\
Jacalin & 61.5 & $8 \mathrm{E}-7$ \\
AMA & $60.1^{\mathrm{c}}$ & $3 \mathrm{E}-15$ \\
RPA & 59.4 & $4 \mathrm{E}-4$ \\
ASA & 58.2 & $4 \mathrm{E}-16$ \\
UDA & 57.7 & $4 \mathrm{E}-5$ \\
WGA & 54.2 & $7 \mathrm{E}-6$ \\
APA & 45.3 & $9 \mathrm{E}-7$ \\
Morniga-G & 37.0 & 0.02 \\
TxLC-I & 36.5 & 0.03 \\
\hline
\end{tabular}

${ }^{\text {a }}$ Data are expressed as mean percentages of deterrent activity, based on a minimum of 2 repeated experiments, each consisting of 2-3 oviposition boxes.

b $p$-values after Student's $t$-test (2-tailed) comparing the effect in the treatment with the control.

c Data from Table 2.

the core of high mannose is as active as the GNA-related lectins. The two chitin-binding lectins, UDA and WGA, also caused a $54-58 \%$ reduction of the oviposition. PNA, which specifically recognizes terminal galactose residues and hence strongly differs for what concerns its specificity from the other legume lectins tested is (nearly) as active as PHA, RPA and ConA in the binary choice experiments. The obvious difference in deterrent activity between jacalin and Morniga-G (64\% and 37\%, respectively) is difficult to 


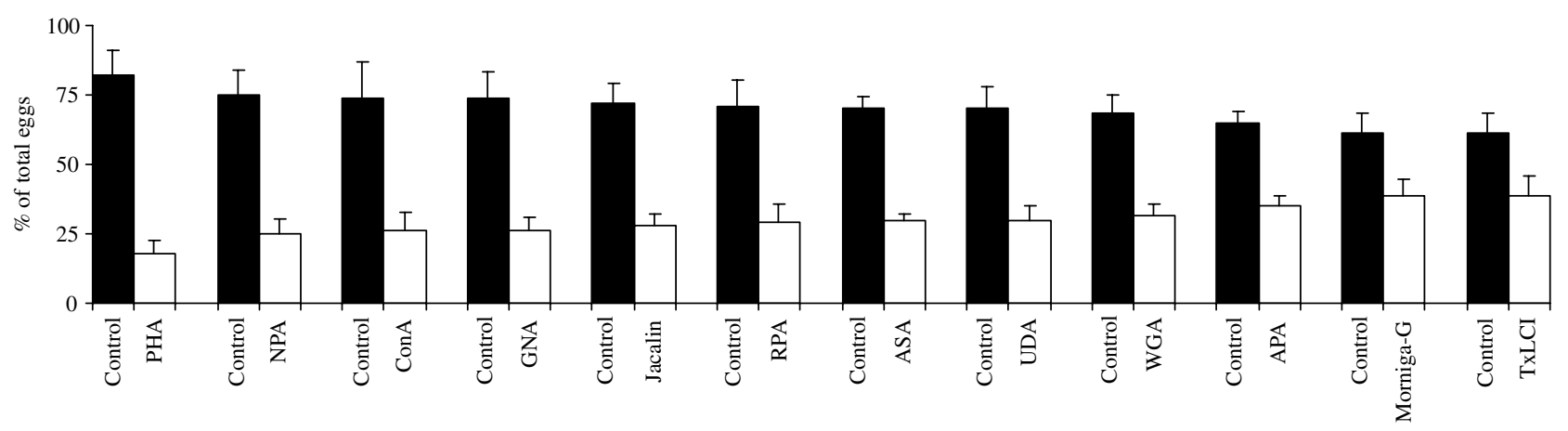

Fig. 2. Distribution of eggs deposited by 20 C. maculatus adults in the oviposition chamber with control seeds and seeds coated with lectin at $0.05 \%$. The total number of eggs laid in each treatment was set at $100 \%$. Data are expressed as means \pm SEM, based on a minimum of two repeated experiments, each consisting of 2-3 oviposition boxes.

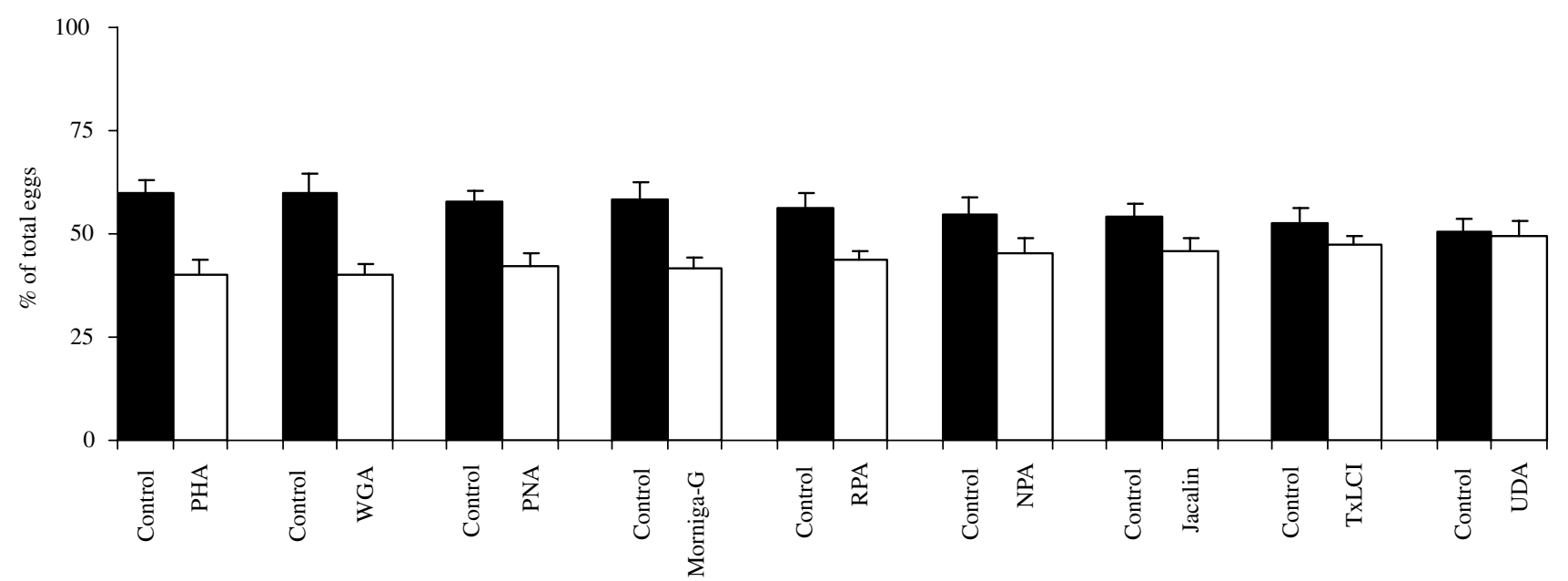

Fig. 3. Distribution of eggs deposited by 30 C. maculatus adults in the oviposition chamber with control seeds and seeds coated with lectin at $0.05 \%$. The total number of eggs laid in each treatment was set to $100 \%$. Data are expressed as means \pm SEM, based on a minimum of two repeated experiments, each consisting of 2-3 oviposition boxes.

reconcile with the fact that both lectins are closely related and exhibit an identical specificity towards the T-antigen disaccharide (Galß1,3GalNAc). A possible explanation might be that there is a difference in specificity towards more complex glycans. Of all lectins the tulip lectin TxLC-I, which possesses two different carbohydrate domains with a distinct specificity, was the least active $(37 \%)$ against oviposition.

\subsection{The deterrent activity of the plant lectins decreases upon enhancing insect density}

To check the influence of insect density on the deterrent activity of the lectins, binary choice assays were repeated for nine plant lectins at a higher insect density. As shown in Table 4, exposure of the lectin-treated cowpeas to 30 instead of 20 unsexed adults in the oviposition chamber markedly reduced the inhibitory activity. Only 5 out of the 9 lectins exhibited a significant deterrent activity at increased insect density. Maximal deterrent action was scored for PHA $(33 \%)$. No significant deterrent action on C. maculatus $(p>0.08)$ was observed for the lectins NPA, Jacalin, TxLC-I and UDA.

\subsection{Effect of lectin treatment of the seeds on emergence and development of adults}

To test whether the lectin present on the seed surface affects the emergence and development of the insects the eventual number of adults was determined 30 days after

Table 4

Deterrent activity of nine plant lectins against oviposition of $30 \mathrm{C}$. maculatus adults

\begin{tabular}{lll}
\hline Lectin, $0.05 \%$ & $\%$ Deterrent activity $^{\mathrm{a}}$ & $p$-value \\
\hline PHA & 33.2 & $7 \mathrm{E}-5$ \\
WGA & 32.9 & $3 \mathrm{E}-4$ \\
Morniga-G & 28.9 & $1 \mathrm{E}-3$ \\
PNA & 27.2 & $7 \mathrm{E}-5$ \\
RPA & 21.4 & $5 \mathrm{E}-3$ \\
NPA & 17.1 & 0.08 \\
Jacalin & 14.8 & 0.07 \\
TxLC-I & 10.4 & 0.19 \\
UDA & 2.2 & 0.82 \\
\hline
\end{tabular}

${ }^{\text {a }}$ Data are expressed as mean percentages of deterrent activity, based on a minimum two replicated experiments, each consisting of 2-3 oviposition boxes.

b $p$-values after Student's $t$-test (2-tailed) comparing the effect in the treatment with the control. 
the onset of the binary choice assays. The emergence rate was not affected by the insect density during the infestation phase. The percent of adult emergence for the eggs deposited on seeds coated with $0.05 \%$ lectin ranged between $97.4 \%$ and $99.5 \%$ (data not shown).

\section{Discussion}

Virtually, all previous studies dealing with the possible noxious effects of plant lectins on insects involved exclusively experiments with artificial diets supplemented with purified lectins. Though straightforward these experiments yielded only information about the direct toxicity of orally administered lectins and did not allow distinguishing repellent or deterrent activities. To corroborate possible adverse effects of plant lectins that are not based on oral toxicity a set of binary choice experiments was set up aimed at identifying the insects' ability to avoid lectin containing plant materials.

The results of the above described binary choice experiments clearly demonstrate for the first time that an application of plant lectins to the surface of chickpeas dramatically reduces the oviposition by $C$. maculatus. Since the reduction in egg number is clearly dose dependent and, in addition, heat inactivated lectin and BSA exhibit no effect, one can reasonably assume that the observed deterrent activity is dependent on a specific biological activity of the lectin. Though it is tempting to speculate that the deterrent activity is somehow related to the carbohydrate-binding activity of the lectins there is no obvious link between the potency of the lectins and their specificity. It should also be emphasized that representatives of all four lectin families tested caused a comparable reduction of oviposition. This is an important observation because it demonstrates that structurally unrelated lectins provoke a similar complex response in the insects.

Hitherto no other examples have been reported of proteins that cause a reduction of insect oviposition in binary choice experiments. However, a similar dose-dependent activity was also reported for the commercial chemical repellent $N, N$-diethyl- $m$-toluamide (DEET) in assays with Spodoptera littoralis (Boisd.) (Stevens et al., 2005). Coating of seeds with a $1 \%$ solution of DEET caused a $80 \%$ reduction of the oviposition of C. maculatus, which is comparable to the inhibition brought about by the lectins AMA $(60 \%)$ and PNA $(64 \%)$ when applied at a concentration of $0.05 \%$.

Indirect evidence for a possible deterrent activity of a plant lectin was also shown by Guzman-Maldonado et al. (1996) who investigated the relationship between physical and chemical characteristics of common bean (Phaseolus vulgaris L.) varieties and their susceptibility to Zabrotes subfaciatus (Boh.). Experiments with Z. subfaciatus in a no-choice experiment indicated that both oviposition and adult emergence are correlated with the lectin content of the bean cultivars but not with seed hardness, seed coat thickness, tannin, trypsin inhibitor or protein content. It was shown that the bean cultivar Flor de Mayo Baijo with the highest lectin content was resistant to $Z$. subfaciatus. Under no-choice and free-choice conditions the adult emergence of $Z$. subfaciatus was reduced to $43.4 \%$ and $68.8 \%$, respectively.

Coating of chickpeas with lectins definitely reduces the oviposition but apparently has no effect neither on egg hatching nor on adult emergence. Since only the egg laying behavior of the insects was affected in our assay system it cannot be excluded that some of the lectins exhibit an oral toxicity to the larvae or adults. Taking into account that the proteins were applied in a thin film at the seed surface the amount of lectin taken up by the insect during their transit from the surface to the inner part of the seed might simply be too small to have a noxious effect.

The observed deterrent activity is not solely determined by the lectins because the eventual effect is for a great deal also determined by the insect density. It is possible that large numbers of $C$. maculatus adults physically remove some of the lectin layer when exploring the seeds, thus dimensioning the repellent effect of the lectin.

Though the results of the binary choice experiments leave no doubt that insects are capable of distinguishing lectin coated from control seeds it remains unclear what sensory system they use to detect the presence of these proteins. It is well documented that the insect's sensory mechanisms are very important for behavior regulation of survival and reproduction, including location of food resources, selection of mates and determination of oviposition sites (Hekmat-Scafe et al., 2002; Ban et al., 2003). Messina et al. (1987a,b) reported that the maxillary and labial palpi of $C$. maculatus are the main organs used in host discrimination and egg-spacing behavior. The chemoreception is presumably mediated by small soluble proteins that are abundantly present in the lymph of chemosensilla, and different classes of chemosensory proteins have been identified in different insects. However, it remains to be demonstrated that the chemosensory proteins are capable of specifically recognizing a wide range of plant lectins.

Irrespective of the exact nature of the employed sensory mechanism insects are apparently capable of 'sensing' potentially harmful plant proteins. In principle, this particular ability can be exploited to develop novel concepts for insect control that are both animal and environment friendly.

\section{Experimental}

\subsection{Insects}

A continuous stock colony of $C$. maculatus was reared under standard conditions $\left(25 \pm 1{ }^{\circ} \mathrm{C} ; 65 \pm 5 \%\right.$ relative humidity and a $16 \mathrm{~h}$ light photoperiod). The insects were fed on untreated chickpea seeds (Cicer arietinum L.) from a commercial source (Smagghe et al., 1996; Stevens et al., 2005). 


\subsection{Lectins}

The 14 plant lectins used in this study were purified to homogeneity using a combination of affinity chromatography and ion exchange chromatography as described previously (Van Damme et al., 1998b, 2002), and are essentially pure as judged by SDS-PAGE. Table 1 presents a list of the different lectins tested, their classification, sugar specificity and molecular structure.

\subsection{Oviposition chamber}

To assess the deterrent effects of plant lectins on oviposition of C. maculatus, we used a binary choice oviposition chamber that is based on the apparatus developed by Laudani and Swank (1954). The oviposition chamber consisted of a rectangle box of clear transparent plastic $(15 \mathrm{~cm}$ long, $15 \mathrm{~cm}$ wide, $7 \mathrm{~cm}$ high) in which five small petri dishes $(5 \mathrm{~cm}$ in diameter, $1 \mathrm{~cm}$ high) were placed in a specific arrangement (one in the center of the box and the four others equidistantly from the center). During the whole length of the experiment, the oviposition chamber was closed with a cloth mesh to prevent insect escape and allow air ventilation, and kept under the standard rearing conditions described above.

\subsection{Binary choice bioassay}

Chickpea seeds were obtained from a commercial source. All experiments (and rearing) were performed with a single batch of chickpeas. Seeds of equal size were selected, dipped into the lectin solution for $1 \mathrm{~min}$, and air-dried prior to exposing to cowpea weevil adults for oviposition (Elhag, 2000). All lectins were dissolved in water. Control seeds were treated with water. In parallel assays, seeds were treated with BSA (bovine serum albumin from Applichem GmbH Co., Darmstadt, Germany) and heatinactivated (i.e. autoclaved for $20 \mathrm{~min}$ at $120^{\circ} \mathrm{C}$ ) AMA. In the binary choice oviposition chamber, two samples of 10 lectin-treated seeds were placed in two petri dishes positioned opposite of each other. Samples of 10 control seeds were deposited in the two remaining peripheral petri dishes. At the beginning of the experiment 20 or 30 unsexed adults of $C$. maculatus were transferred from the rearing stock into the petri dish placed in the center of the oviposition chamber. After $24 \mathrm{~h}$ the adult beetles were removed from the oviposition chamber, and the numbers of eggs attached to each chickpea seed counted under a stereomicroscope. Seeds were put back in the oviposition chamber to follow the development of the attached eggs and score the emergence rate of adults (after 30 days).

\subsection{Statistical analysis}

The deterrent effect of each lectin was quantified by measuring the reduction of the number of deposited eggs in comparison to the number of eggs laid on control seeds.
The percentage of deterrent activity was determined by calculating the reduction in oviposition following the equation: $\left[\left(N_{\mathrm{C}}-N_{\mathrm{T}}\right) / N_{\mathrm{C}}\right] \times 100$, where $N_{\mathrm{C}}=$ number of eggs deposited on control chickpea seeds and $N_{\mathrm{T}}=$ number of eggs laid on treated chickpea seeds. The results are expressed as means \pm SEM based on a minimum of two independent experiments, each consisting of 2-3 oviposition chambers. The significance of differences between means (lectin-treated chickpea seeds as compared to control seeds) was analyzed using a Student's $t$-test.

\section{Acknowledgements}

A. Sadeghi is recipient of a doctoral grant from the Ministry of Science and Technology and Kurdistan University, Iran. This research is supported by Project 3G016306 of Fund of Scientific Research (FWO-Vlaanderen, Brussels, Belgium).

\section{References}

Ban, L., Scaloni, A., Brandazza, A., Angeli, S., Zhang, L., Yan, Y., Pelosi, P., 2003. Chemosensory proteins of Locusta migratoria. Insect Mol. Biol. 12, 125-134.

Boeke, S.J., Van Loon, A., Van Huis, A., Dicke, M., Kossou, D.K., 2004. Toxicity and repellence of African plants traditionally used for the protection of stored cowpea against Callosobruchus maculatus. J. Stored Prod. Res. 40, 423-438.

Boulter, D., Edward, G.A., Gatehouse, A.M.R., Gatehouse, J.A., Hilder, V.A., 1990. Additive protective effects of incorporating two different higher plant-derived insect resistance genes in transgenic tobacco plants. Crop Prot. 9, 351-354.

Carlini, C.R., Grossi-de-Sa, M.F., 2002. Review plant toxic proteins with insecticidal properties. A review on their potential as bioinsecticides. Toxin 40, 1515-1539.

Elhag, E.A., 2000. Deterrent effects of some botanical products on oviposition of cowpea bruchid Callosobruchus maculatus (F.) (Coleoptera: Bruchidae). Int. J. Pest Manage. 46, 109-113.

Gatehouse, A.M.R., Powell, K.S., Van Damme, E.J.M., Peumans, W.J., 1995. Insecticidal properties of plant lectins their potential in plant protection. In: Pustzai, A., Bardocz, S. (Eds.), Lectins: Biomedical Perspectives. Taylor and Francis, London, pp. 35-58.

Guzman-Maldonado, S.H., Main-Jarilo, A., Catellanos, J.Z., González de Mejía, E., Acosta-Gallegosc, J.A., 1996. Relationship between physical and chemical characteristics and susceptibility to Zabrotes subfasciatus (Boh.) (Coleoptera: Bruchidae) and Acanthoscelides obtectus (Say) in common bean (Phaseolus vulgaris L.) varieties. J. Stored Prod. Res. 1, 53-58.

Hekmat-Scafe, D.S., Scafe, C.R., McKinney, A.J., Tanousy, M.A., 2002. Genome-wide analysis of the odorant-binding protein gene family in Drosophila melanogaster. Genome Res. 2, 1357-1369.

Hilder, V.A., Powell, K.S., Gatehouse, A.M.R., Gatehouse, J.A., Gatehouse, L.N., Shi, Y., Hamilton, W.D., Merryweather, A., Newell, C.A., Timans, J.C., Peumans, W.J., Van Damme, E.J.M., Boulter, D., 1995. Expression of snowdrop lectin in transgenic tobacco plants results in added protection against aphids. Transgenic Res. 4, 18-25.

Laudani, H., Swank, G.R.S., 1954. A laboratory apparatus for determining repellency of pyrethrum when applied to grain. J. Econ. Entomol. 47, 1104-1107.

Machuka, J.S., Okeloa, O.G., Chrispeels, M.J., Jackai, L.E.N., 2000. The African yam bean seed lectin affects the development of cowpea weevil but does not affect development of larvae of the legume pod borer. Phytochemistry 53, 667-674. 
Messina, F.J., Barmore, J.L., Renwick, J.A.A., 1987a. Oviposition deterrent from eggs of Callosobruchus maculates: spacing mechanism or artifact? J. Chem. Ecol. 13, 219-226.

Messina, F.J., Barmore, J.L., Renwick, J.A.A., 1987b. Host selection by ovipositing cowpea weevils: patterning of input from separate sense organs. Entomol. Exp. Appl. 43, 169-173.

Murdock, L.L., Huesing, J.E., Nielsen, S.S., Pratt, R.C., Shade, R.E., 1990. Biological effects of plant lectins on the cowpea weevil. Phytochemistry 29, 85-89.

Oliveira, A.E.A., Sales, M.P., Machado, O.L.T., Fernandes, K.V.S., Xavier-Filho, J., 1999. The toxicity of Jack bean (Canavalia ensiformis) cotyledon and seed coat proteins to the cowpea weevil (Callosobruchus maculatus). Entomol. Exp. Appl. 92, 249-255.

Omitogun, O.G., Jackai, L.E.N., Thottappilly, G., 1999. Isolation of insectidal lectin-enriched extracts from African yam bean (Sphenostylis stenocarpa) and other legume species. Entomol. Exp. Appl. 90, 301311.

Peumans, W.J., Van Damme, E.J.M., 1995. Lectins as plant defense proteins. Plant Physiol. 109, 347-352.

Shaaya, E., Kostjukovski, M., Eilberg, J., Sukprakarn, C., 1997. Plant oils as fumigants and contact insecticide for the control of stored-product insects. J. Stored Prod. Res. 33, 7-15.

Shade, R.E., Murdock, L.L., Foard, D.E., Pomeroy, M.A., 1986. Artificial seed system for bioassay of cowpea weevil (Coleoptera: Bruchidae) growth and development. Environ. Entomol. 15, 12861291.

Sharma, H.C., Sharma, K.K., Crouch, J.H., 2004. Genetic transformation of crops for insect resistance: potential and limitation. Crit. Rev. Plant Sci. 23, 47-72.
Silver, P., 1994. Alternatives to methyl bromide sought. Pesticide News 24, $12-27$.

Singh, S.R., 1997. Cowpea cultivars resistant to insect pests in world germplasm collection. Trop. Grain Legume Bull. 9, 3-7.

Smagghe, G., Salem, H., Tirry, L., Degheele, D., 1996. Action of a novel insect growth regulator tebufenozide against different developmental stages of four stored product insects. Parasitica 52, 61-69.

Stevens, C.V., Smagghe, G., Rameloo, T., De Kimpe, N., 2005. Insect repellent/antifeedant activity of 2, 4-methanoproline and derivatives against a leaf and seed-feeding pest insect. J. Agric. Food Chem. 53, 1945-1948.

Van Damme, E.J.M., Peumans, W.J., Barre, A., Rougé, P., 1998a. A composite of several distinct families of structurally and evolutionary related proteins with diverse biological roles. Crit. Rev. Plant Sci. 17, 575-692.

Van Damme, E.J.M., Peumans, W.J., Pusztai, A., Bardocz, S., 1998b. Handbook of Plant Lectins: Properties and Biomedical Applications. Wiley, Chichester, pp. 452.

Van Damme, E.J.M., Hause, B., Hu, J., Barre, A., Rougé, P., Proost, P., Peumans, W.J., 2002. Two distinct jacalin-related lectins with a different specificity and sub-cellular location are major vegetative storage proteins in the bark of the black mulberry tree. Plant Physiol. 130, 757-769.

Zettler, J.L., Cuperus, G.W., 1990. Pesticidal resistance in Tribolium castaneum (Coleoptera: Tenebrionidae) and Rhysopertha dominica (Coleoptera: Bostrichidae) in wheat. J. Econ. Entomol. 83, 1677-1681.

Zhu-Salzman, K., Salzman, J.R.A., Koiwa, H., Shade, R.E., Balfe, S., 2003. Fusion of soybean cysteine, protease inhibitor and a legume lectin enhances anti-insect activity synergistically. Agric. Forest Entomol. 5, $317-323$. 